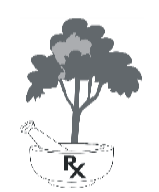

https://dx.doi.org/10.4314/jpb.v18i3.7

Vol. 18 no. 3, pp. 223-236 (September 2021)

http://ajol.info/index.php/jpb
Journal of
PHARMACY AND
BIORESOURCES

\title{
Exploring patients' viewpoints on uncomplicated malaria and its management in primary healthcare facilities of Plateau State, Nigeria: a qualitative study
}

\author{
Nanloh S. JIMAM ${ }^{1 *}$, Nahlah E. ISMAIL ${ }^{2}$, Shalkur DAVID ${ }^{1}$, Benjamin N. JOSEPH ${ }^{1}$, \\ Michael A. ADENIYI', Victory O. OLUTUASE ${ }^{1}$, Pandell A. DAMUN¹, Rotkang C. \\ OKUNLOLA ${ }^{1}$
}

\begin{abstract}
${ }^{1}$ Department of Clinical Pharmacy and Pharmacy Practice, Faculty of Pharmaceutical Sciences, University of Jos, Jos. Nigeria. ${ }^{2}$ Department of Clinical Pharmacy, Faculty of Pharmacy, MAHSA University, Selangor, Malaysia.
\end{abstract}

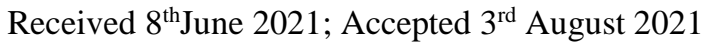

\begin{abstract}
Malaria infection is a major public health problem in Nigeria. The present study explored patients' thoughts and feelings on uncomplicated malaria and its management practices in some primary healthcare (PHC) facilities of Plateau state, Nigeria. An in-depth interview was conducted on patients receiving treatment in some of the facilities in the state, who were recruited through purposive sampling method up to saturation point. All the information was audio-recorded and transcribed verbatim before analysis using the principles of thematic content analysis of inductive method. Generally, their views on malaria-related issues were categorised into four main themes based on their relevancies as: patients' perceptions on malaria infection and anti-malarial drugs, the role of healthcare workers and family during treatment, medications taken and socio-economic-related factors, as well as their general views on healthcare facilities-related factors. The study showed patients' perceptions of the aforementioned factors as influencing their treatment and management practices of the disease in the study area. Necessary interventions that would improve patients' quality of management of the disease toward achieving the desired outcome of therapy are recommended.
\end{abstract}

Keywords: Drug-related practices, Patients' viewpoints, Primary healthcare facilities, Uncomplicated malaria

\section{INTRODUCTION}

Studies have shown high levels of inappropriate use of medications among patients, whose reasons could be intentional, whereby the patients actively decide on their own not to use treatment or follow treatment recommendations due to several reasons. These reasons include cultural and religious belief systems of the patients, patients' level of understanding, and side effects of the medications. Sometimes the patients stop the medication when the symptoms of the ailment disappeared thinking that they are better [1 5]. Similarly, patients' reasons for not taking medications correctly could be unintentional, in which case the patients' unplanned behaviours could be linked to many reasons. These could be associated with cognitive reasons leading to patients forgetting to take their medications or how to use the medication.

*Correspondence. E-mail: jimamnanloh@gmail.com Tel: +234-8020318993.

ISSN 0189-8442

2021. Published by Faculty of Pharmaceutical Sciences, University of Jos, Nigeria. Under Creative Commons Attribution-Non-Commercial 4.0 International License. https://creativecommons.org/licenses/by-nc/4.0/ 
Furthermore, the complexity of a medication regimen (polypharmacy) and the patient's memory, leading to forgetfulness to take the drug at the prescribed time or poor recall of instructions of how to take the drug $[2,5,6]$. It may even be due to economic reason, among others [1,7]. Previous studies have reported the negative effects of lack of knowledge and trust on patients' health beliefs and treatment seeking behaviours [2, $8-10]$, in addition to their use of drugs, which could result in pathogen's resistance to medications when wrongly used [11 - 14].

Despite the endemic nature of the disease in this part of the world [15 - 17], there was scanty information on patients' perspectives on possible determinants of their uncomplicated malaria management practices, especially in the rural settings of Nigeria. To gain detailed understanding of respondents' behavioural characteristics and other related factors, there was need to conduct qualitative research since it is associated with the social constructivist and interpretive paradigm which emphasises the socially constructed nature of reality. Usually, an inductive approach is adopted amongst qualitative researches, which may involve theory development as a framework for the research or looking for a pattern of meaning based on the collected data $[18,19]$. An in-depth interview is mostly preferred over the focus group discussion approach $[18,19]$. It enables the researcher to establish rapport with the respondents, which will enhance cooperation, in addition to having the advantage of allowing the researcher to clarify ambiguous answers when and where appropriate. It is about recording, analysing, and attempting to uncover the deeper meaning and significance of human behaviours and experiences, including contradictory beliefs, behaviours, and emotions [18]. This is made possible through the use of information known as variables (in words) which are collected using various methods including unstructured or semi-structured techniques $[19,20]$.
The questions are open-ended and respondents are probed during the interviews to encourage them to provide more details and clarifications [18, 21]. This approach though, may be expensive and time consuming but studies have shown that qualitative in-depth interviews assist in providing respondents' perspective into the study which gives more understanding on their reasons for any poor or good management practices and will further give more meaning to any related quantitative data $[18,22,23]$. This is relevant in the present study because reality depends on one's mental structure and activities [24]. Hence, the purpose of the present qualitative study was to explore views on disease-, PHC facilities-, and drug-related practices involving patients with uncomplicated malaria. This was with a view to better understand the factors they perceived as influencing their treatment and management practices of uncomplicated malaria in sampled PHC facilities of Plateau state, Nigeria.

\section{EXPERIMENTAL METHODS}

Study design and setting. The study was a cross-sectional qualitative survey using faceto-face in-depth interview research methods [18] to gain a detail understanding of factors influencing patients' uncomplicated malarial treatment and management practices. This study was conducted across selected PHC facilities (Pil-Gani, Jarmai, and Bukuru Central) in Plateau state, Nigeria. The state is divided into the southern, central, and northern zones, with a total landmark of 30,913 square kilometers and a population of $5,178,712$ people, based on the 2006 census [25]. Reliability and validity of the qualitative study were ascertained by making sure that the study was appropriately designed, the right sampling method was used, with correct data collection, analysis, and interpretations as explained by Creswell [18] and Kura [19].

Sampling method and sample size calculation. Unlike quantitative studies in which the generalizability of the research is 
ensured by getting required sample populations that were true representations of the entire population of studies using appropriate sampling method [26], such is not the main purpose in qualitative researches as reported by Silverman [27]. Instead, respondents are identified based on their possession of certain characteristics that the interviewer feels would be important in exploring information that would be relevant to the study [28]. The purposive sampling method was used to recruit respondents in the in-depth interviews that could give more informative views regarding uncomplicated malaria and its management and treatment [18, 29]. This sampling method was chosen because it was considered more appropriate for recruiting interviewees who were fluent in English and with sufficient cognitive ability to participate in the interviews to ensure maximum variability. This would serve to increase the quality of the interview and also the data. It might also strengthen the theoretical generalization of the research findings, in addition to the fact that constant comparison was used to contextualize participants' information with relevant literature during analysis as explained by Silverman [27]. Adequate number of respondents participated in the interview to get enough materials for more understandings on uncomplicated malaria management, which was guided by the concept of saturation and sample size criteria reported by Sandelowski [30] and Francis et al.[31].

Ethics approval. This study was approved by the Joint Research Review and Ethics Committee, Research Management Centre (RMC), MAHSA University, Malaysia through an approval letter reference RMC/EC01/2016, dated 25/11/2016. This approval was subsequently used to obtain permission from the Plateau state Ministry of Health, Jos, Nigeria, and the Directors of Primary Health Care PHCs of the selected
Primary Healthcare Centers located in the appropriate LGAs before data collection.

Interview guide. A semi-structured in-depth interview guide consisting of relevant key items related to the topic of study was developed with some flexibility to allow divergence for more detailed information, with inputs from experts in the field of study [32]. This interview guide was then pilot-tested by conducting interviews with three volunteers and later transcribed to determine the appropriateness of the flow of questioning and language employed. Modifications were made where necessary, to ensure that the order of interview items enables the patient speak on the subject sequentially.

Data collection. A semi-structured interview guide containing open-ended questions was used to conduct in-depth patients' interviews. The interview continued until there was no new information emerging from the respondents, indicating saturation, after which two more interviews were conducted as confirmation [18]. The overall number of respondents that participated in the interview was 14. All the interviews, which were conducted by the researcher in the English language were audio-taped using Samsung Galaxy 110 and later transcribed for analysis. To make the respondents feel relaxed and confident, the researcher created a friendly environment, ensuring only the researcher and the respondents were around before the start of the interviews. The interview lasted between 20 and 30 minutes per respondent.

Data analysis. Qualitative data analysis involves the explanation of the interactions between interviewees and the content of the text, by changing or transforming the raw textual data collected by a researcher into results $[18,33]$. It has been well documented that qualitative data could be analysed through two methods known as deductive and inductive approaches [18]. The former used a predetermined framework to analyse data, by 
imposing some of the possible themes that could be responsible for the findings [18]. The second approach to qualitative data analysis is the inductive method which involves the use of the data to arrive at the outcome of the analysis without any predetermined framework [18]. This could be considered a better approach in the present study based on the present research objectives.

The audio textual data was transcribed and summarised into word writing manually, and counter-checked by listening to the audiotape several times for correction of possible errors and statements not transcribed into written form. In addition, the anonymity of the patients was ensured by tagging their transcribed information using codes such as patient number 1 , male, 24 years old, without revealing their actual identities.

The principles of thematic content analysis [18, 33] were followed during the analysis by studying the details of the textual data from which recurring codes having the same or similar meanings were grouped into themes as summarised in Figure 1:

\section{RESULTS}

Fourteen (14) positive uncomplicated malaria patients receiving treatment for the disease across the 3 senatorial zones of Plateau state participated in the semi-structured interviews. About $42.86 \%$ of them were from the southern zone of the state, while $35.71 \%$ and $21.43 \%$ were from central and northern senatorial zones, respectively (Table 1). Many of them $(57.14 \%)$ were females and their mean ( \pm SD) age was $29.64( \pm 6.83)$ with age ranged between 23 to 50 years old. A total of $42.86 \%$ of the interviewees were employed, with a mean $( \pm$ SD) monthly salary of 22, $714.29( \pm$ 17, 661.03) Naira. Many of them (42.86\%) earned between 18, 000 and 40, 000 Naira per month.

Viewpoints of patients regarding uncomplicated malaria disease and its management. The in-depth interviews demonstrated that patients were able to fluently express their different views related to uncomplicated malaria infection and its management in PHC facilities of Plateau state based on their various notions about the subject matter (Table 2). Appropriate verbatim quotations of the respondents were inserted to demonstrate their views as explained by Burnard et al. [34]. The illustrative extracts were identified by patients' number, age, and gender, and were placed in italic script. Although these cannot be regarded as representative of the widespread position of the other patients on any single issue regarding malaria disease and management as the study participants were purposively recruited to participate in the interviews, such responses were nevertheless useful in indicating the varying views of the patients on key matters, and in some cases, provided evidence in support of factors that might influence patients' uncomplicated malaria management practices.

The respondents' views on the disease and its management were catalogued into main themes based on their relevancies as:

1. Patients' perception on malaria disease and drugs

2. Patients' perceptions on the role of healthcare workers and family

3. Patients' perceptions on taking of medications and socio-economic-related factors

4. Patients' general views on health facilitiesrelated factors

\section{Patients' perception on malaria disease} and drugs. Following introduction, the indepth interviews commenced by exploring the interviewees' general perceptions regarding malaria infection and its management. The interviewees expressed varying views regarding what malaria disease and medications are, which were categorised into three subthemes, including their perceived knowledge on transmission, symptoms, and the required anti-malarial medicines. Regarding their notions on the transmission of 
the disease, most of them recognised mosquitoes as the main vector for transmitting malarial disease which was an indication of their level of awareness on the disease. However, their understanding of the parasitic protozoan, Plasmodium falciparum which is responsible for about $98 \%$ of malaria cases in Nigeria [16] was limited. In addition, many identified environmental-related factors that encourage the breeding and survival of mosquitoes including dirty and busy environments, and water reservoirs, as illustrated in some of the patients' quotes below.

“... When I or any of my family members start presenting symptoms like high temperature, fever, vomiting, and weakness of the body, I normally assume the presence of malaria fever, therefore take the antimalarial drug immediately."

Patient No. 3; 23 years old; male

“... You know that malaria fever is very common this time of the rainy season when mosquitoes are plenty. Some of the common symptoms of the disease include vomiting, high body temperature, weakness of the body. It can sometimes make somebody fall down."

Patient No. 8; 30 years old; female

Another patient also stated that:

“... Malaria infection is a kind of disease caused by mosquitoes, the symptoms include high body temperature, vomiting, weakness of the body, and when you go to hospital or chemist, they will give chloroquine and panadol for curing the disease.... Sometimes they will also give you some tiny tablet to take before the chloroquine".

Patient No. 7; 24 years old; female

2. Patients' perceptions on the role of healthcare workers and family. The Primary Healthcare Centre (PHC) is the first level of contact for individuals, families, and communities with the national health system bringing healthcare as close as possible to where people live and work, and constitutes the first element of a continuing healthcare process. Hence, it plays major role in the management of malaria infection and other related common ailments, especially within the rural community settings with no secondary or tertiary healthcare facilities. The use of patients' views is important in exploring their perspectives and experiences on the quality of healthcare services received at the healthcare facilities and possible problems that might influence their outcomes of treatment, although, there might be variation in the expression of such views based on individual differences in term of expectations, experiences, and satisfactions

The patients felt been cared for when they were engaged in the care process through enough patients-healthcare workers' interactions time to enable them to present their complaints and appropriately addressed by the healthcare workers. Such relationships make the patients to understand the problem and the need for treatment, which might positively influence their management practices of the disease. The patients' views expressed during the interviews regarding the quality of healthcare they received from healthcare workers showed that many of them were not satisfied with the services because of the way they were handled by the healthcare workers in the PHC facilities. Poor communication occurred between healthcare workers and patients. In addition, many patients did not freely communicate with the healthcare workers as they were afraid of being insulted because of the arrogance and rudeness exhibited by the workers as narrated by some of the patients.

“... I am not always happy with the kind of care received in the healthcare facility, because most of the time I happen to visit the PHC facility, I hardly see people to attend to me immediately, because they are not plenty in the facility, and will be attending to other patients... you have to wait until when for your turn to before you will be attended to."

Patient No. 1; 23 years old; male

“... The health personnel gives less attention to patients, instead, they are harsh, not treating their client as patients, some of them write the instruction on dispensing envelop on how to take the drugs, with some explanations, while others just write 2 three times a day inscription on the envelopes without explanations."

Patient No. 7; 24 years old; female 
“... The behaviours of the PHC workers toward patients is not good, sometimes I preferred going to a private clinic where adequate attention is given to me."

Patient No. 9; 30 years old; female

On the contrary, other patients disagreed with the perception that the quality of services rendered by healthcare workers in the PHC was not satisfactory as narrated by patient No. 8.

"... I am satisfied with their services because they are polite to me and give me medicines that cure my disease."

Patient No. 8; 30 years old; male

The perceived roles of immediate family members in helping during the management of the disease were also recognised by the interviewees such as the provision of food, reminders on when to take medications, and other related patients care to ensure they adhere to medications as exclaimed by some of the interviewees. On a general note, such positive support received from the family members might influence patients' medication usage, hence, improve treatment outcome of the disease.

“... I really thank my family for all their care to me through provision of food to take before taking my drugs. They also remind me of the time for taking my drugs."

Patient No. 2; 25 years old; male “... Due to my nature of work, I sometimes forget to take my drugs at the right time, that is why my wife always advise me stay at home when on treatment so that she would be monitoring the timing. And I am also the type of person that only remembers to take drugs when I start feeling symptom of the disease, but stop once I feel okay."

Patient No. 3; 23 years old; male

Respondent No. 9 also shared similar views with patient No. 3 as illustrated in his quotation below:

“... I am the type of person that doesn't like taking medicine. Once the symptom goes, I always try to avoid taking the drugs. My family always pressurised me to complete the medication as instructed."

Patient No. 9; 30 years old; male

\section{Patients' perceptions on taking of medication} and socio-economic-related factors. A good understanding of patients' perception of malaria and its medications could be important in better understanding the perceived factors that might influence their treatment and management practices of the disease. The earlier perceived communication gap between the patients and healthcare workers during management of the disease might also influence their adherence to medications as earlier illustrated in patients' quotes. Several perceived factors were mentioned by the participants during the interviews as responsible for influencing their malaria management practices.

Some of the patients treated for malaria infection mentioned the fear of possible side effects due to anti-malarial drugs as reasons that negatively influenced their willingness to complete the medication. For instance, some of them complained of experiencing gastrointestinal-related problems when on ACT medications, and some also complained of the bitter taste of chloroquine.

“... I always prefer chloroquine when I have malaria because it is very cheap compared to other drugs like ACT, although it is very bitter in my mouth when I am swallowing it."

Patient No. 3; 23 years old; male

“... I feel like vomiting, and sometimes vomit, and have a headache when I take the drugs."

Patient No. 4; 26 years old; male

Some of the patients indicated that forgetting to take their medications at the right time was one of the factors influencing their adherence to malaria medication. Sometimes, due to busy schedules, they missed the dose.

“... When I go for social gatherings like political meetings, I sometimes reach home late, though I still take my drugs even when the stated time has passed."

Patient No. 8; 30 years old; male

“... Considering the nature of my business that when you are not there, things seem not to be working well, most especially that my staff strength is low, that makes me to attend to my clients, when I am feeling better even though, still on medication. On some days that many 
clients patronize the premises, I will be too busy to a point of missing my afternoon dose."

Patient No. 11; 50 years old; female

Another patient further stated that during management of uncomplicated malaria, once he feels relieved of the symptom, he keeps the remaining drugs in case of any future attack.

“... Once I feel okay, I don't bother to continue taking the medicine again, I keep the tablets in my locker so that I might take again anytime I have malaria infection, as you know that the disease is very common during this wet season"

Patient No. 3; 23 years old; male

Similarly, poor living conditions were explained by most of the respondents as factors influencing their medication-taking behaviours, especially related to unavailability of food, transportations to healthcare facilities, and money to pay for drugs. Some of them stated their fear of taking drugs on an empty stomach because of fear of the side effects; hence, they postponed taking drugs anytime they do not have food to take as narrated by some of the respondents:

“... Poverty is really biting us in the village, sometimes I don't have enough money to buy the prescribed antimalarial drugs. Instead, I will just buy paracetamol to relieve the pains. Even when I buy the drug and there is no food to eat, I feel reluctant in taking the drugs."

Patient No. 3; 23 years old; male

“... Sometimes I don't have money to treat myself, and even when I manage to get my drugs, I am always afraid to take it on empty stomach due to lack of money to buy food."

Patient No. 8; 30 years old; male

"Lack of money sometimes hinders me from going to the hospital to seek for treatment when I am ill."

Patient No. 2; 25 years old; male

“... As you can see by yourself the type of bad road in this village, when one fall sick, especially in the night, you hardly get means of transportation to convey you to healthcare facility. It becomes worse the day it rain, because is only motorcycle that would be able to fly the road and their charges are usually high during such situation. There are no options other than to comply and pay them if you can afford since you cannot trek because of the distance."

Patient No. 14; 38 years old; female
Respondents' cultural, general and religious beliefs about malaria and its medications were also expressed as factors influencing their medication-taking behaviours. One of the respondents said certain categories of patients like pregnant women and children were restricted from taking medications because of their beliefs that orthodox medicine has unwanted effects.

“... Sometimes too much of farming under the sun can make someone to have malaria and we normally recognise that when the eye or urine change to yellow."

Patient No. 13; 30 years old; male

Another interviewee also had a different belief regarding malaria fever as narrated:

“... As a believer, I know that God made us in His own image and makes all things available to us to enable us live a healthy and balance life on this earth. I strongly believe that most of the sicknesses we experience are satanic attack."

Patient No. 2; 25 years old; female

A respondent also stated his strong belief in the effectiveness of chloroquine to the extent that he did not seem to agree with any other drug prescribed and dispensed to him for uncomplicated malaria treatment.

"... There is this malaria drug called chloroquine, I always buy and take anytime I have malaria, and it is very effective because once I take the first dose plus Panadol, all the symptoms will disappear... Life keeps on going",

Patient No. 3; 23 years old; male

Patient No.6 further narrated as follows:

“... There is the general belief among our people that drugs have unwanted effects on pregnancy, hence, once a woman is pregnant, she is restricted from taking drugs, especially when they are unfamiliar with such drug."

Patient No. 6; 28 years old; male

Instead, some preferred traditional medicine:

“... My culture does not allow me to take orthodox drugs always. Our people believe that traditional medicine is a better option."

Patient No. 13; 30 years old; male

“... Malaria is very common during rainy season. There is one plant that our people commonly called 'ikuniribik' in Tarok language, and we usually pluck it 
and place by the door and windows of sleeping room to stop mosquitoes from entering the room. When someone falls sick of malaria, the person is treated at home by boiling the leaves of a plant called neem and the person will drink morning and evening and also bath with it." We only visit hospital when the condition gets worse."

Patient No. 7; 24 years old; female

Other patients further mentioned practicing religious activities such as fasting as the main hindrance to not appropriately taking medications:

“... When I am performing my religious obligations such as fasting, it will not allow me to take my medications at the appropriate time because Ifeel afraid to take it on empty stomach."

Patient No. 1; 23 years old; male

“... Sometimes medicines don't seem to work faster for me in healing my ailment anytime I am sick. That is why I so much believe in seeking for God's divine intervention through prayers anytime I or any of my family members fall sick more than depending on medicines."

Patient No. 2; 25 years old; female

\section{Patients' general views on health} facilities-related factors. Lastly, when asked if they had anything else not captured in the interview that was important to them and wanted to share with the interviewer, many of them mentioned accessibility to PHC facilities, poor quality drugs and unavailability of drugs and trained health personnel as some of the poor experience they encountered during their visits to the healthcare facilities for malaria management. Accessibility implied how easily the patients can physically locate the healthcare facilities and get quality care from qualified healthcare workers, while the availability of drugs implied the existence of recommended quality anti-malarial drugs to be prescribed and dispensed to the patients in need. The lack of these aspects in the PHC facilities implied that patients have to look for means of transport to the far distant facilities where they can access the optimum care. Many of them did not have means of transportation, except public transports which produced financial implications among poor citizens.

“... You will visit some of the healthcare facilities with great expectations of getting the needed attention from the healthcare workers, but you will find out that the facility don't have enough workers to attend to you. They will keep you there for long before been attended to if you are lucky, the worst of it is that after you receive prescription, they will tell you that the drug is not available.... and that is how some patients end up dying as a result of common ailments."

Patient No. 9; 30 years old; female

“... One of the problems we are facing is that we don't have any PHC in the community. We travelled a long distance to obtain medical care, and sometimes I don't get transport money to go for treatment. Means of transportation... you know that is important, especially in emergency situations to convey patient to nearby healthcare facility."

Patient No. 10; 33 years old; male

“... Even when I manage to visit the healthcare facility, most of the drugs prescribed are not always available. We have to go to the chemist to buy, which is more expensive and I have also noticed that some of the drugs given to us have expired."

Patient No. 11; 50 years old; female

To help in curtailing some of these limitations, the patients pleaded for the employment of more qualified staff and training of those on ground to improve patienthealthcare workers' relationships, which could in turn, improve patients' medication practices as exclaimed by one of the respondents:

“... There is a shortage of staff in the facilities especially during this rainy season that malaria incidence is rampant. I plead that more qualified staff be employed in the health facilities."

Patient No. 11; 50 years old; female

“... The few available staff in the clinic are not enough to adequately attend to us because of the overwhelming number of patients that patronize the healthcare facility. I will like you to help us tell government to employ more nurses and also train those that are on ground to improve in their services to us."

Patient No. 1; 23 years old; male 
N.S. Jimam et al. / J. Pharmacy\&Bioresources18(3), 223-236 (2021)

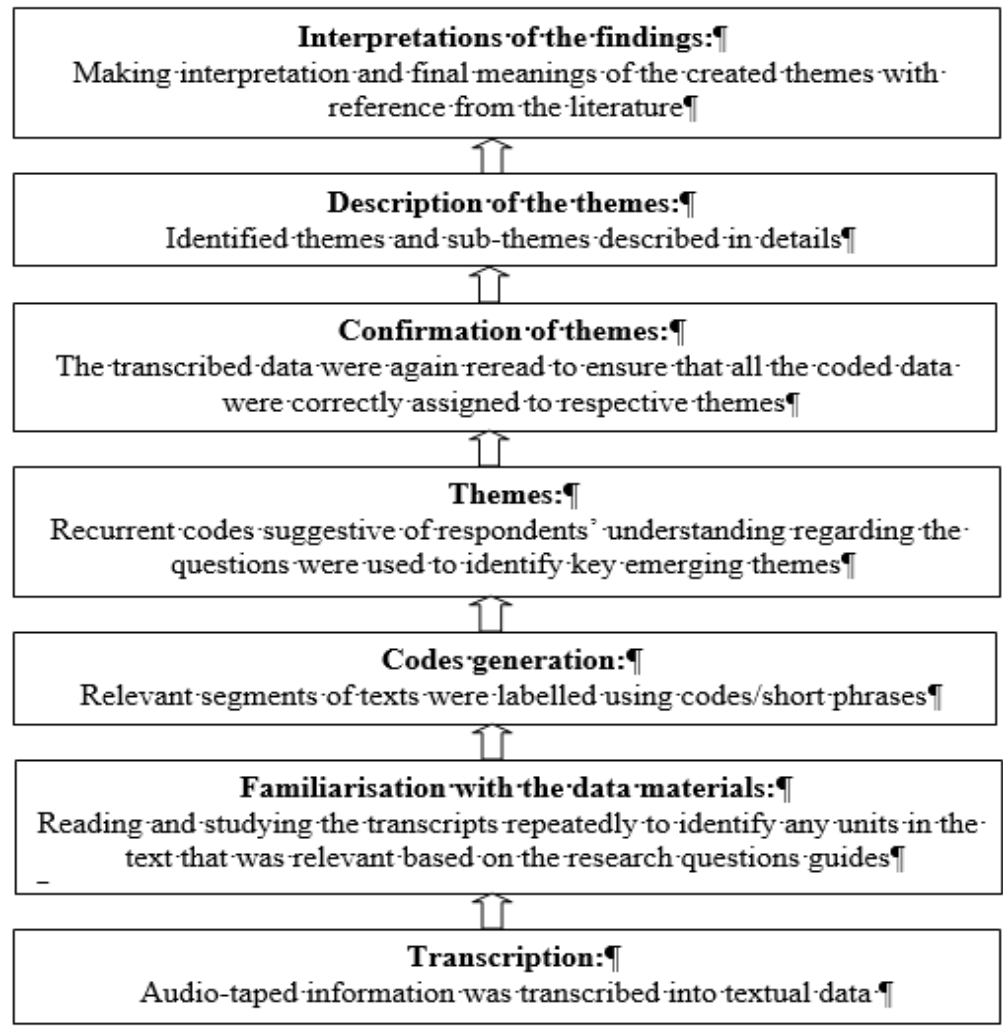

Figure 1: Summary of steps followed during analysis of qualitative data

Table 1: Demographic characteristics of respondents $(\mathrm{N}=14)$

\begin{tabular}{|c|c|c|c|}
\hline & Characteristics & $\mathrm{n}(\%)$ & Descriptive statistics \\
\hline \multirow[t]{3}{*}{ Senatorial zones } & South & $6(42.86)$ & \\
\hline & Middle & $5(35.71)$ & \\
\hline & North & $3(21.43)$ & \\
\hline \multirow[t]{2}{*}{ Gender } & Male & $6(42.86)$ & \\
\hline & Female & $8(57.14)$ & \\
\hline \multirow[t]{6}{*}{ Age (years) } & Mean $( \pm$ SD $)$ & & $29.64( \pm 6.83)$ \\
\hline & Median (IQR) & & $29(6)$ \\
\hline & Minimum - Maximum & & $23-50$ \\
\hline & $18-29$ & $7(50.00)$ & \\
\hline & $30-41$ & $6(42.86)$ & \\
\hline & $>41$ & $1(7.14)$ & \\
\hline \multirow[t]{2}{*}{ Marital status } & Never married & $5(35.71)$ & \\
\hline & Married & $9(64.29)$ & \\
\hline \multirow[t]{2}{*}{ Education level } & Secondary education & $8(57.14)$ & \\
\hline & Higher education & $6(42.86)$ & \\
\hline \multirow[t]{3}{*}{ Occupation } & Student & $3(21.43)$ & \\
\hline & Employed & $6(42.86)$ & \\
\hline & Farmer/business & $5(35.71)$ & \\
\hline \multirow[t]{7}{*}{ Monthly income (A) } & Mean $( \pm$ SD) & & $22,714.29( \pm 17,661.03)$ \\
\hline & Median (IQR) & & $21,000(4,000)$ \\
\hline & Minimum - Maximum & & $0-50,000$ \\
\hline & None & $3(21.43)$ & \\
\hline & $<18,000$ & $3(21.43)$ & \\
\hline & $18,000-40,000$ & $6(42.86)$ & \\
\hline & $>40,000$ & $2(14.28)$ & \\
\hline
\end{tabular}


Table 2: Patients' viewpoints on uncomplicated malaria and management in PHC facilities of Plateau state ( $\mathrm{N}=14)$

\begin{tabular}{lc}
\hline Initial coding framework & Themes \\
\hline $\begin{array}{l}\text { Knowledge on transmission } \\
\text { Knowledge on symptoms }\end{array}$ & $\begin{array}{c}\text { 1. Patients' perception on malaria infection and } \\
\text { drugs }\end{array}$ \\
\hline $\begin{array}{l}\text { Patients-healthcare workers' relationships } \\
\text { Satisfaction with services provided by healthcare workers }\end{array}$ & $\begin{array}{c}\text { 2. Patients' perceptions on role of healthcare } \\
\text { workers and family }\end{array}$ \\
Family as reminder and provider of care & \\
\hline $\begin{array}{l}\text { Fear of possible side effects of medication } \\
\text { Forgetfulness }\end{array}$ & \\
$\begin{array}{l}\text { Incomplete course of medications } \\
\text { Busy schedule }\end{array}$ & $\begin{array}{c}\text { 3. Patients' perceptions on taking of medications and } \\
\text { socio-economic-related factors }\end{array}$ \\
$\begin{array}{l}\text { Religire and beliefs about malaria and its medications } \\
\text { Poor living conditions: - Lack of food } \\
\quad \text { - Lack of money }\end{array}$ & \\
$\quad$ - Unaffordable transportation & \\
\hline $\begin{array}{l}\text { Access to PHC facilities } \\
\text { Unavailability of drugs in facilities }\end{array}$ & 4. Patients' general views on health facilities- \\
Poor quality of drugs in facilities \\
Unavailability of trained health workers
\end{tabular}

\section{DISCUSSION}

Malaria is one of the major public health problems in Nigeria where Plateau state is located, and the causes of a high prevalence of the disease have been linked with medicallyrelated and non-medically related factors, with subsequent health and economic burdens on both the patients and the system. Despite variations in respondents' views on what malaria disease and its management were all about, their responses helped in providing perspective into the study which gave more understanding on factors that influence their management of the disease. The respondents' perceived knowledge on the disease and its management indicated likelihood of their being aware of mosquitoes as the common vector that transmits the disease, which is similar to a study conducted in Nigeria by Adetola et al. [36]. However, their perception of the common symptoms of uncomplicated malaria was fair. Similarly, their viewpoints regarding the recommended anti-malarial drugs for managing the ailment indicated poor understanding as many of them were unable to correctly recognise ACTs as the recommended drug for managing uncomplicated malaria in
Nigeria. This observation agreed with similar reports by Uzochukwu et al. [37].

The outcome of the in-depth interviews also indicated poor healthcare workerspatients' relationships, especially as it relates to patients' counselling on the importance of completing the regimen coupled with financial constraint and fear of perceived unwanted effects of orthodox medicines. The general beliefs that most medicines for treating malaria are not genuine ones were also perceived by the interviewees as contributing factors to any observed gaps in their management practices of uncomplicated malaria in PHC facilities. Good level of interaction might likely influence patients' levels of understanding and perceptions on the disease and its management. This is capable of improving their adherence to therapy, as reported by Altaras et al. [38], which indicated the association between good healthcare patients' interactions on malaria diagnosis and management.

Many of the interviewees admitted occasionally forgetting to take anti-malarial medication. This might be linked to a cognitive impairment such as low memory and the complexity of a medication regimen which 
interfered with their uncomplicated malaria medication practices, as it makes them to either forget to take the drug at the prescribed time or poor recall of instructions on how to take the drug $[2,5,6]$. Furthermore, some of the patients reported stopping the anti-malaria medication when they felt unwell or ill, while others could not afford to complete the course of medications based on their financial capability. Such a practice would encourage parasite resistance to drugs resulting in treatment failure $[17,39,40]$. Proper counselling would enable the patients to understand the disease, to correctly take their anti-malarial drugs, and the need to diligently adhere to instructions on how to take the medications. Such approaches have been reported to help in improving patients' adherence to medications [41]. Pre-packaging of the drugs separately with their names written and instructions on how and when to take them might also help in solving the patients' memory deficits.

Some other wealth of information relating to factors that both hindered and helped the patients from appropriately carrying out their medication practices included their busy schedule and receiving support from immediate families. Less busy patients might have a better time to spend during the management of the disease as there would be less distraction during medication. On the contrary, the appropriate management of the disease by patients with busy schedules became more difficult, with the risks of compromising or forgetting to take their medications. In addition, the amount of support patients received from the family in term of reminders on time for medicationtaking and general care were perceived as interventions that influenced their uncomplicated malaria management practices.

Furthermore, the perceived negative influences of socio-cultural factors might be overcome through a good level of healthcare patients' interactions which would impact required understandings and trust in patients, with possibility of changing their general negative perceptions on the disease and its medications [7, 42]. For instance, the restriction of pregnant women and children from taking medications as observed during the interview could be based on the communities' beliefs on the toxicity of orthodox medicines on the developing foetus and children compared to the herbs. Many of them also believed that herbal products were more efficacious than the orthodox and this belief and practices have been part of their ways of life, hence, could influence their attitudes and behaviours [43]. In addition, some of them testified that their religious practices like fasting sometimes affect their commitment to the appropriate intake of medications. Financial weakness among the respondents is one of the common perceived reasons for their likely poor management practices for the disease as narrated during the interviews. According to them, lack of money to pay for costs associated with both preventive and curative management of the disease were major problems they were passing through, hence, most of them were unable to visit healthcare facilities for medication, until when the situation gets worse.

Access to both human and material resources in the PHC was also described by many of the interviewees as a hindrance to accessing quality care during malaria management. The negative impact of lack of access to health services on the patronage of people for quality care in health facilities in malaria-endemic areas has been also reported by Sulemana and Dinye [44]. These researchers also reported that people living far from health services were likely to suffer more from the disease than those who have such services closer to them. Similar impacts have also been observed in situations where the health facilities are available without the availability of quality drugs or trained staff as reported in previous studies [38]. 
Limitations. Although the sample size of the participant was dictated through the data saturation criterion [31], their views might not be the general views of larger populations that were receiving treatment in the same PHC facilities across Plateau state whose ideas were not captured during the interviews. Furthermore, due to limiting the study to only patients receiving treatment for uncomplicated malaria in government PHCs in the state, their thoughts and feelings might not be generalizable to other patients receiving similar treatment in private health facilities in the state, or in PHCs across other states in Nigeria.

\section{Conclusion}

Findings from the qualitative in-depth interviews revealed patients' perceptions on malaria disease and anti-malarial drugs, role of healthcare workers and family during treatment, medications taking and socioeconomic-related factors, and patients' general views on healthcare facilities as related factors that influence their management and treatment of uncomplicated malaria. In order to improve patients' quality of treatment and management of the disease in Nigeria, a similar study should be replicated among patients across private and public PHCs, as well as secondary and tertiary health facilities in the country to explore views of patients about uncomplicated malaria and its treatment and management for necessary interventions.

\section{Acknowledgements}

The authors acknowledge the assistance and support of the officers-in-charge and other staff of PHCs visited, and the interviewees in ensuring that the research work was successfully conducted. The Plateau State Commissioner of Health and the Directors of PHCs of the various LGAs are highly appreciated for their prompt approval and permission to conduct the study.

\section{REFERENCES}

1. Brown MT, Bussell JK. Medication adherence: WHO Cares? Mayo Clinic Proceed. 2011; 86(4): 304 - 314. doi:10.4065/mcp.2010.0575.

2. Greenley RN, Kunz JH, Walter JBA, Hommel KA. Practical strategies for enhancing adherence to treatment regimen in inflammatory bowel disease. Inflammatory Bowel Disease,2013; 19(7), 15341545. doi:10.1097/MIB.0b013e3182813482.

3. Haynes RB, Ackloo E, Sahota N, Mcdonald H, Yao $\mathrm{X}$. Interventions for enhancing medication adherence (Review). The Cochrane Library; 2008. doi:10.1002/14651858.CD000011.pub3.Copyright.

4. Martin MY, Kim Y, Kratt P, Litaker MS, Kohler CL. Medication adherence among rural, low-income hypertensive adults: A randomized trial of a multimedia community-based intervention. American Journal of Health Promotion, 2011; 25(6): 372-378.

5. Yadav SP, Yadav S, Kuma P, Yadav S. Knowledge, treatment-seeking behaviour and socioeconomic impact of malaria in the desert of Rajasthan, India. Southern African Journal of Epidemiology and Infection, 2013; 28(1): 41-47.

6.Jimmy B, Jose J. Patient medication adherence: measures in daily practice. Oman Medical Journal,2011; 26(3), 155-159. Doi:10.5001/omj.2011.38.

7.Mwenesi HA. Sociocultural and behavioural issues in the treatment and prevention of malaria. Working Group on Malaria, Geneva; 2003. [Online], from: http://www.tropika.net/review/030324Malaria_4/article.pdf [accessed on 23 May, 2017].

8.Eke RA, Diwe KC, Chineke HN, Duru CB, Uwakwe KA. Evaluation of the practice of self-medication among undergraduates of Imo State University (IMSU) Owerri, South-East Nigeria. Orient Journal of Medicine, 2014; 26 (3-4): 79-83.

9.Liu J, Isiguzo C, Sieverding M. Differences in malaria care seeking and dispensing outcomes for adults and children attending drug vendors in Nasarawa, Nigeria. Tropical Medicine and International Health, 2015; 20(8): 1081-1092. doi:10.1111/tmi.12520.

10.Rosenbaum L, Shrank WH. Taking our medicineimproving adherence in the accountability era. The New England Journal of Medicine, 2013; 369(8): 694-695.

11.Afolabi A. Factors influencing the pattern of selfmedication in an adult Nigerian population. Annals of African Medicine, 2008; 7(3): 120-127.

12.Bennadi D. Self-medication: A current challenge. Journal of Basic and Clinical Pharmacy,2014; 5(1): 19-23. 
13.Kotwani A, Ewen M, Dey D, Iyer S, Lakshmi PK, Patel A, et al. Prices \& availability of common medicines at six sites in India using a standard methodology. Indian Journal of Medical Research, 2007; 125(5): 645-654.

14.Zurovac D, Githinji S, Memusi D, Kigen S, Machini B, Muturi A, et al. Major improvements in the quality of malaria case-management under the "test and treat', policy in Kenya. PLoS ONE,2014; 9(3): e92782. doi:10.1371/journal.pone.0092782.

15.Edet-Utan O, Ojediran T, Usman S, AkintayoUsman NO, Fadero T, Oluberu OA, Isola, I.Knowledge, perception and practice of malaria management among non-medical students of higher institutions in Osun State Nigeria. American Journal of Biotechnology and Medical Research, 2016; 1(1): 5-9. doi: 10.5455/ajbmr.20151226010533.

16.Fana SA, Danladi M, Bunza A, Anka SA, Imam AU. Prevalence and risk factors associated with malaria infection among pregnant women in a semi-urban community of north western Nigeria. Infectious Diseases of Poverty, 2015; 4(24). doi:10.1186/s40249-0150054-0.

17.World Health Organisation (WHO). World malaria report, Geneva, 2017. Licence: CC BY-NC-SA 3.0 IGO; 2017. [[Online], from: https://apps.who.int/iris/bitstream/handle/10665/259 492/9789241565523-eng.pdf [accessed on $20^{\text {th }}$ July, 2018].

18.Creswell JW. 2014. Research design, qualitative, quantitative, and mixed methods approaches (4th ed.). USA: Sage Publications. http://doi.org/10.1007/s13398-014-0173-7.2.

19.Kura SYB. Qualitative and quantitative approaches to the study of poverty - Taming the tensions and appreciating the complementarities. The Qualitative Report, 2012; 17(34), 1-19.

20.Nouri AI, Abdi AM, Hassali MA. Synopsis of research methodologies: a brief guide for pharmacists. Journal of Pharmaceutical Research International, 2018; 24(5), 1-16. doi:10.9734/JPRI/2018/42207.

21.Al-Busaidi ZQ. Qualitative research and its uses in healthcare. Sultan Qaboos University Medical Journal, 2008; 8(1): 11- 19. From: http://www.pubmedcentral.nih.gov [Accessed on 16 July, 2017].

22.Bendassolli PF. Theory building in qualitative research:reconsidering the problem of induction. Qualitative Social Research, 2013; 14(1): 25. http://doi.org/http://www.qualitativeresearch.net/index.php/fqs/article/view/1851.

23.Green BN, Johnson CD. Establishing a theoretical basis for research in musculoskeletal epidemiology: A proposal for the use of biopsycho-social theory in investigations of back pain and smoking. Journal of Chiropractic Humanities, 2013; 20(1): 1-8. http://doi.org/10.1016/j.echu.2013.10.004.

24.Tuli F. Review article the basis of distinction between qualitative and quantitative research in social science : reflection on ontological, epistemological and methodological perspectives. Ethiopian Journal of Education and Sciences, 2010; 6(1), 97-108. Doi:10.4314/ejesc.v6i1.65384.

25.National population commission (NPC) [Nigeria], national malaria control programme (NMCP) [Nigeria], \& ICF international. (2012). Nigeria Malaria Indicator Survey 2010. [ONLINE] Available at: http://dhsprogram.com/what-wedo/survey/survey-display-392.cfm. [Accessed 16 April 2018].

26.Elmannan AAA, Elmardi KA, Idris YA, Spector JM, Ali NA, Malik EM. Anti-malarial prescribing practices in Sudan eight years after introduction of artemisinin-based combination therapies and implications for development of drug resistance. $B M C$ Pharmacology and Toxicology, 2015; 16(3). doi:10.1186/s40360-015-0002-4.

27.Silverman D. Doing Qualitative Research: A Practical Handbook. London: Sage; 2000.

28.Pope C, Ziebland S, Mays N. Analysing qualitative data. British Medical Journal, 2000; 320(7227): 114116

29.Patton MQ. Qualitative Research \& Evaluation Methods(3rd ed.). London, UK: Sage; 2002.

30.Sandelowski M. Sample-size in qualitative research. Research in Nursing and Health,1995; 18(2):179183.

31.Francis JJ, Johnston M, Robertson C, Glidewell L, Entwistle V, Eccles MP, Grimshaw JM: What is an adequate sample size? Operationalising data saturation for theory-based interview studies. Psychology and Health,2010; 25(10), 1229-1245. doi:10.1080/08870440903194015.

32. Britten N. Qualitative interviews in healthcare. In Pope C, Mays N (eds) Qualitative research in health care. BMJ Books, 2nd ed, London; 1999.

33.Yin RK. Qualitative research from start to finish. New York: The Guilford Press; 2011. [Online], from: www.guilford.com [accessed on 24 November, 2017].

34.Burnard P, Gill P, Stewart K, Treasure K, Chadwick $\mathrm{B}$. Analysing and presenting qualitative data. Br Dent J 2008; 204(8): 429-432. doi: 10.1038/sj.bdj.2008.292.

35.Fitzpatrick JL, Sanders JR, Worthen BR. Programme 
evaluation. Alternative Approach and Practical guidelines. 3rd edition. Boston: Library of Congress; 2004.

36.Adetola OT, Aishat LL, Olusola O. Perception and treatment practices of malaria among tertiary institution students in Oyo and Osun States, Nigeria. Journal of Natural Sciences Research,2014; 4(5): 30 33.

37.Uzochukwu BSC, Ossai EN, Okeke CC, Ndu AC, Onwujekwe OE. Malaria knowledge and treatment practices in Enugu state, Nigeria: a qualitative study. International Journal of Health Policy and Management, 2018; 7(9): 859-866. doi:10.15171/ijhpm.2018.41.

38.Altaras R, Nuwa A, Agaba B, Streat E, Tibenderana JK, Martin S, Strachan CE. How do patients and health workers interact around malaria rapid diagnostic testing, and how are the test experienced by patients in practice? A qualitative study in western Uganda. Plos ONE, 2016; 11(8): e0159525. doi:10.1371/journal.pone.0159525.

39.Federal Ministry of Health (FMOH). National Guidelines for Diagnosis and Treatment of Malaria (3rd Edition) Abuja; 2015.
40.Tangpukdee N, Duangdee C, Wilairatana P, Krudsood S. Malaria diagnosis: a brief review. Korean Journal of Parasitology, 2009; 47(2): 93102. doi:10.3347/kjp.2009.47.2.93.

41. Khantikul N, Butraporn P, Kim HS, Leemingsawat $\mathrm{S}$, Tempongko MASB, Suwonkerd W. Adherence to anti-malarial drug therapy among vivax malaria patients in northern Thailand. Journal of Health, Population, and Nutrition, 2009; 27(1): 4-13

42.Schilder AJ, Kennedy C, Goldstone IL, Ogden RD, Hogg RS, O'Shaughnessy MV. "Being dealt with as a whole person." Care seeking and adherence: The benefits of culturally competent care. Social Science and Medicine,2001; 52(11): 1643-1659.

43.World Health Organization. The World Health Report 2007: A safer future - global public health security in the $21^{\text {st }}$ century, Geneva, 2007. [Online], from: https://www.who.int/whr/2007/en/ [accessed on 7th May, 2017].

44.Sulemana A, Dinye RD. Access to healthcare in rural communities in Ghana: a study of some selected communities in the pru district. European Journal of Research in Social Sciences, 2014; 2(4): 122-132. 